\title{
Inhaltsstoffe aus Pflanzen als Hoffnung bei Viren und resistenten Bakterien
}

Die Erfolge bei der Bekämpfung von bakteriellen Infekten mit Antibiotika haben eine Kehrseite: Resistente Stämme entwickeln sich immer mehr zur Gefahr. Deshalb ist die Suche nach neuen Substanzen, die beim Einsatz bei der Therapie von Infektionen mit resistenten Erregern wirksam sind, wichtig. Es gibt eine ganze Reihe von Pflanzen, die für die Behandlung infrage kommen. Sie könnten auch bei Virusinfektionen verwendet werden.

Für eine ganze Reihe von viralen Erkrankungen gibt es entweder keine oder nur sehr schlecht wirkende Therapien, die zudem bei Virenmutanten, die eine Resistenz entwickelt haben, nicht mehr anschlagen. In einer neuen Übersichtsarbeit beschäftigen sich Reichling et al. (Forsch Komplementmed 2009;16:79-90) unter anderem mit dem Einsatz von Pflanzeninhaltsstoffen in diesem Bereich.

Eine Hoffnung setzt die Forschung auf bisher unbekannte Wirkstoffe aus Pflanzen. Bei vielen von ihnen ist eine antimikrobielle Wirkung nachgewiesen oder zumindest nach den Erfahrungen der Praktiker wahrscheinlich. So weiss man, dass Fenchel (Foeniculum vulgare), Pfefferminze (Mentha pipertia) oder Thymian (Thymus vulgaris) gegen Gram-positive und -negative Bakterien wirken - wie auch gegen Hefe, andere Pilze und Viren. In einer Übersichtsarbeit, die Wissenschafter aus Zürich und Heidelberg jetzt veröffentlicht haben, stellen sie die Erkenntnisse zum Potenzial von Pflanzenwirkstoffen in der antimikrobiellen Therapie zusammen.

Es gibt nur wenige effiziente Mittel mit antiviraler Wirkung. Dazu gehören etwa Arzneimittel, die bei einer Infektion mit dem HI-Virus gegeben werden. Acyclovir, mit dem eine Herpes-Infektion behandelt wird, verhindert die Replikation des Virus. Verschiedene ätherische Öle waren auch bei Resistenz des Virus gegen Acyclovir noch wirksam.
Die meisten antiviralen Substanzen blockieren die Vermehrung des Virus in der Zelle oder verhindern, dass er mit seiner RNA bzw. DNA eine Körperzelle infiziert.

Eine ganze Reihe von Pflanzen, bei denen antimikrobielle Eigenschaften nachgewiesen wurden, könnte sich für die Therapie von Infektionen mit resistenten Stämmen eignen. Helicobacter pylori ist ein Gram-negatives Bakterium, das für die chronische Gastritis verantwortlich und bei der Entstehung von Adenokarzinomen beteiligt ist. Die Therapie besteht aus der Gabe von zwei Inhibitoren für die Protonenpumpen und zwei Antibiotika. Es gibt neuerdings Hinweise, dass verschiedene pflanzliche Substanzen, wie etwa Alkaloide, Flavonoide oder Polysaccharide, und verschiedene Pflanzenextrakte gegen $H$. pylori wirken. In den letzten Jahren sind Studien zu knapp 25 Pflanzenarten veröffentlicht worden, die als essentielle Öle eine Wirkung gegen Helicobacter haben. Dabei wirkt ein knappes Dutzend bereits im Konzentrationsbereich von deutlich weniger als $100 \mu \mathrm{g} / \mathrm{ml}$, während andere erst bei einer doppelt so hohen Konzentration Wirkung zeigten. In Tierversuchen wirkten sie auch gegen resistente Helicobacter-Stämme. Am aktivsten waren die essentiellen Öle aus der Karotte (Daucus carota), die bereits bei einer Konzentration von $20 \mu \mathrm{g} / \mathrm{ml}$ wirkten. In einem sauren Milieu scheint die Wirkung der essentiellen Öle stärker zu sein. Einige
Forscher vermuten, dass sie sich deshalb als Nahrungsbeigabe bei der Standardbehandlung von Gastritis eignen könnten.

Mycoplasma ist die Ursache einer untypischen Lungenentzündung, die bei Jugendlichen zwischen 5 und 15 Jahren und bei Erwachsenen zwischen dem 30. und dem 35. Lebensjahr auftritt. Zur Behandlung wurden hauptsächlich Tetrazykline und Makrolide eingesetzt. In den letzten Jahren sind Mycoplasma-Stämme gefunden worden, die gegen Makrolide resistent sind. Bei der Behandlung von M. pneunomia mit dem Öl des Teebaums (Metaleuca alternifolia) verändert das Bakterium seine Form. Normalerweise ist es birnenförmig. Nach der Behandlung ist es rund und ähnelt der nicht virulenten Form. Nun wird vermutet, dass das Öl das intrazelluläre Skelett angreift und dabei so verändert, dass der Erreger einen Teil seiner Gefährlichkeit einbüsst. Die Zellmembran, sonst ein Angriffspunkt für Antibiotika, wird scheinbar nicht zerstört.

Das Öl des Teebaums wirkt auch gegen Staphylococcus aureus, das ein Problem in Spitälern ist, in denen Methicillin-resistente Stämme Patienten infizieren. Auch auf Staphylococcus wirkt es wahrscheinlich dadurch, dass es zu morphologischen Veränderungen im Zellinneren führt, die eine Zellteilung verhindern. Andere Untersuchungen belegen eine wachstumshemmende Wirkung bei Escherichia coli. (rfi) 